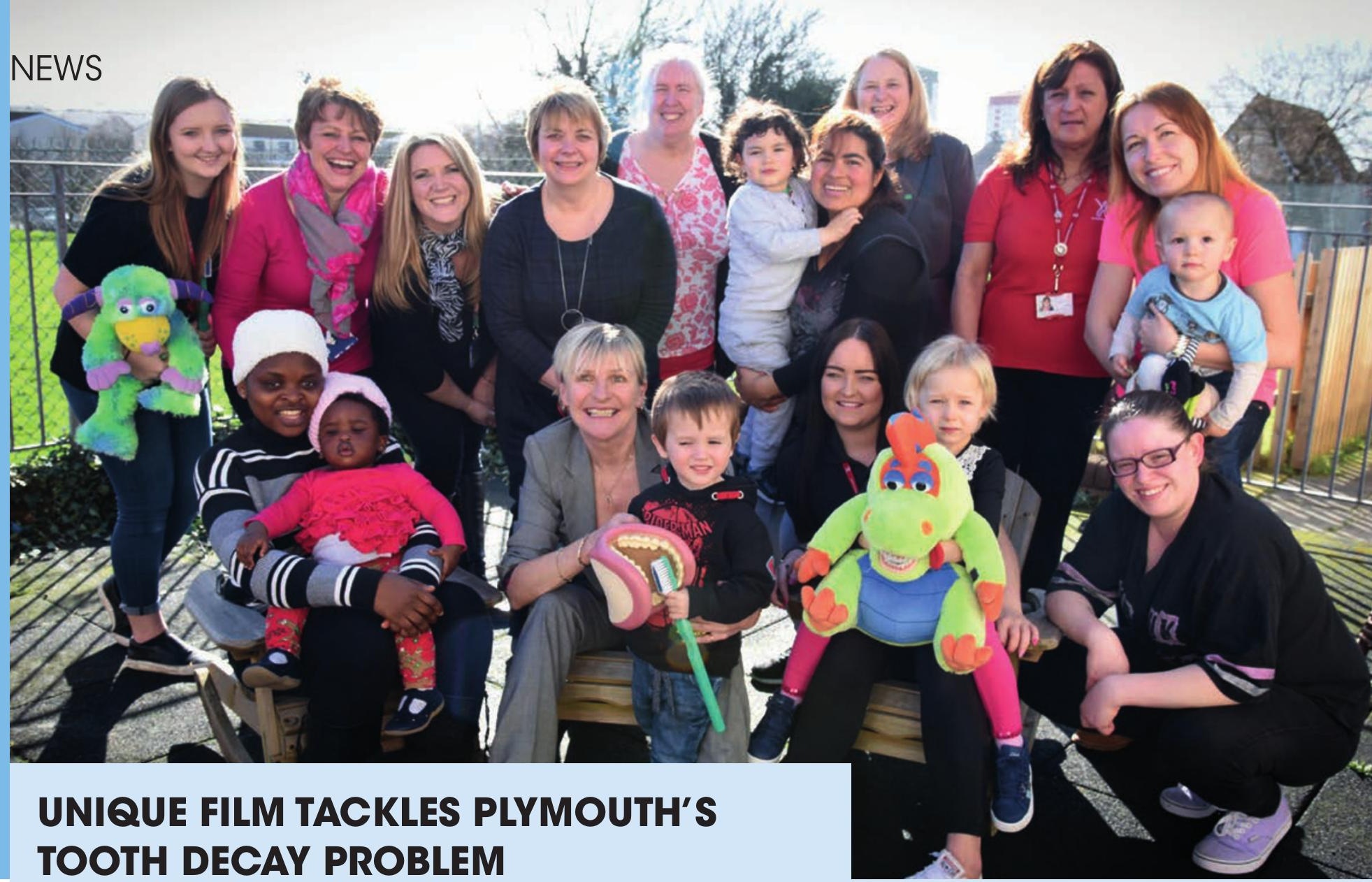

Deninsula Dental Social Enterprise 1 (PDSE), Peninsula Dental School and Plymouth University have produced a unique film aimed at tackling Plymouth's growing tooth decay problem.

The film, 'Open Wide and Step Inside', is a fun and interactive resource to help raise the profile of dental decay and disease and highlight the large number of children who are hospitalised for tooth extraction under general anaesthetic: 848 in Plymouth in 2015-2016.

In March, a special screening of the film was shown to parents and children (pictured) at Action for Children's Green
Ark Children's Centre in Devonport, an area of Plymouth.

The film stars Geoffrey the Giant and his friend Mouse who live in Smeaton's Tower on Plymouth Hoe. Geoffrey has toothache as a result of eating sweets, drinking fizzy drinks and neglecting to clean his teeth properly. Mouse persuades him to visit Daisy the Dentist who finds the problem and gives Geoffrey a filling.

The animation was created by Plymouth University's TELMeD team which produces e-learning tools and materials for medical, dental, Faculty of Health and other students.
Dr Robert Witton, Director of Social Engagement and Community-based Dentistry, PDSE, said: 'We devised and delivered every aspect of the project, which includes the film, teachers' resources and an oral health pack for every child. With more children being admitted to hospital for dental problems than for any health issue, data suggests new and innovative approaches are needed to encourage better cleaning, improved diet and frequent visits to the dentist.

'Our thanks go to the Wrigley Company Foundation, Henry Schein, local schools and the TELMeD team at Plymouth University.

\title{
NEW NEEDLESTICK INJURY SURVEY
}

The British Association of Dental Nurses (BADN) are conducting a new survey into the incidence of needlestick injuries amongst dental nurses working in the UK and the Republic of Ireland, on behalf of Initial Medical.

The survey is a follow up to BADN's 2014 Survey to see if, three years on, the Safer Sharps Regulations have made any difference to the number of needlestick injuries and ways of working in dentistry.

To complete the survey, visit http://bit. ly/2n5sDMn.

The results of the study will be published later this year.

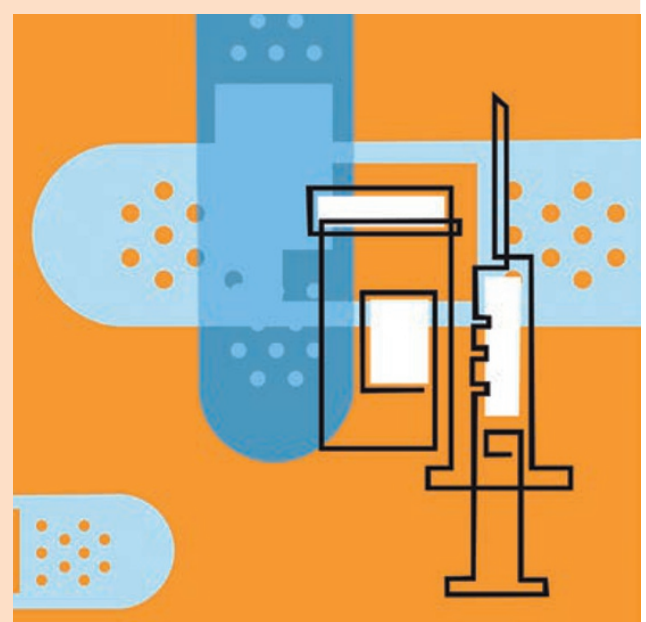

\section{Do you have some news?}

Does your dental practice or workplace within the dental industry have some news to share? Perhaps you have recently taken part in an event to raise money for charity, someone in your team has won an award, you organised a practice open day or oral health education activity in your community? BDJ Team would be delighted to share your news with our audience. Please send the details of your story and a photo to k.quinlan@nature.com. 